\title{
Assessment of Pediatric asthma drug use in three European countries; a TEDDY study
}

\author{
Elif Fatma Sen • Katia M. C. Verhamme • \\ Antje Neubert • Yingfen Hsia • Macey Murray • \\ Mariagrazia Felisi • Carlo Giaquinto • \\ Geert W. 't Jong • Gino Picelli • Eugenio Baraldi • \\ Alfredo Nicolosi • Adriana Ceci • Ian C. Wong • \\ Miriam C. J. M. Sturkenboom • \\ on behalf of the TEDDY European Network \\ of Excellence
}

Received: 4 May 2010 /Accepted: 10 August 2010/Published online: 2 September 2010

(C) The Author(s) 2010. This article is published with open access at Springerlink.com

\begin{abstract}
Asthma drugs are amongst the most frequently used drugs in childhood, but international comparisons on type and indication of use are lacking. The aim of this study was to describe asthma drug use in children with and without asthma in the Netherlands (NL), Italy (IT), and

\section{What is already known}

- Asthma drugs are among the most prescribed drugs to children

- Most frequently used asthma drugs are short-acting beta2-mimetics and inhaled steroids

- There is a large variability in prescription rates between countries
\end{abstract}

\section{What this study adds}

- Off-label use of asthma drugs in children is low

- Linking multi-country databases makes it possible to study country specific pediatric drug use in a systematic manner without being hampered by methodological differences

E. F. Sen $(\bowtie) \cdot$ K. M. C. Verhamme · G. W. 't Jong •

M. C. J. M. Sturkenboom

Department of Medical Informatics,

Erasmus University Medical Center,

Suite Ee 21.55, Dr Molewaterplein 50, P.O. Box 2040,

3000 CA Rotterdam, The Netherlands

e-mail: e.f.sen@erasmusmc.nl

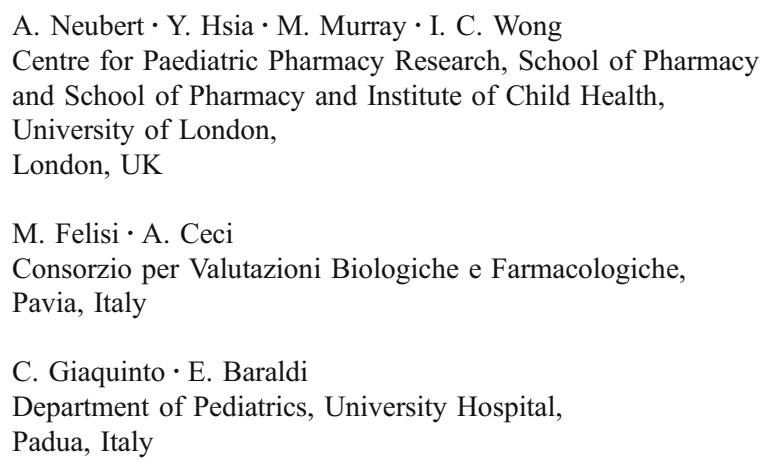

the United Kingdom (UK). We conducted a retrospective analysis of outpatient medical records of children 0 18 years from 1 January 2000 until 31 December 2005. For all children, prescription rates of asthma drugs were studied by country, age, asthma diagnosis, and off-label

G. W. 't Jong

Department of Paediatrics, Sophia Children's Hospital, Erasmus University Medical Center,

Rotterdam, The Netherlands

G. Picelli

International Pharmacoepidemiology and Pharmacoeconomics

Research Center,

Desio, Italy

A. Nicolosi

Department of Epidemiology and Medical Informatics, Institute of Biomedical Technologies, National Research Council, Milan, Italy

A. Nicolosi

G.H. Sergievsky Center, School of Public Health,

Colombia University,

New York, USA 
status. One-year prevalence rates were calculated per 100 children per patient-year (PY). The cohort consisted of 671,831 children of whom 49,442 had been diagnosed with asthma at any time during follow-up. B2-mimetics and inhaled steroids were the most frequently prescribed asthma drug classes in NL (4.9 and 4.1/100 PY), the UK (8.7 and 5.3/100 PY) and IT (7.2 and 16.2/100 PY), respectively. Xanthines, anticholinergics, leukotriene receptor antagonists, and anti-allergics were prescribed in less than one child per 100 per year. In patients without asthma, B2-mimetics were used most frequently. Country differences were highest for steroids, (Italy highest), and for B2-mimetics (the UK highest). Off-label use was low, and most pronounced for B2-mimetics in children $<18$ months (IT) and combined B2-mimetics+ anticholinergics in children $<6$ years (NL). Conclusion: This study shows that among all asthma drugs, B2-mimetics and inhaled steroids are most often used, also in children without asthma, and with large variability between countries. Linking multi-country databases allows us to study country specific pediatric drug use in a systematic manner without being hampered by methodological differences. This study underlines the potency of healthcare databases in rapidly providing data on pediatric drug use and possibly safety.

Keywords Pediatric asthma. Drug utilization

\section{Introduction}

Respiratory drugs are amongst the most frequently prescribed drugs in children, and especially, asthma drugs are frequently prescribed [32]. Prevalence rates of asthma drug use range between $4 \%$ and $26 \%$, depending on country, age range, and study period (Table 1) $[2,6,9,11,12,14,16$, $18,20,21,40,43]$. Asthma is defined as a chronic inflammatory disorder of the airways and is associated with airway hyperresponsiveness that leads to recurrent episodes of wheezing, breathlessness, chest tightness, and coughing [35]. In children aged 5 years and younger, the clinical symptoms of asthma are variable and non-specific. Furthermore, routine testing for main asthma features is not possible in this age group, which hampers making a diagnosis.

According to the Global Initiative for Asthma (GINA), bronchodilators, (inhaled short-acting B2-mimetics, SABA; long-acting B2-mimetics, LABA; anticholinergics, $\mathrm{ACH}$ ), inhaled corticosteroids (ICS), and alternative (add-on) treatments such as leukotriene receptor antagonists (LTRA), xanthines and anti-allergics (cromones) all have a place in the treatment of childhood asthma, although at various stages depending on severity of illness [35]. In pediatrics, asthma is one of the main indications for which these drugs are used.
Apart from these respiratory drugs, systemic glucocorticoids are also used in the treatment of asthma. However, due to side effects such as potential adrenal suppression and growth impairment with long-term use [33, 35], use of systemic glucocorticoids in asthmatic children is restricted to asthma exacerbations and very severe persistent asthma [35].

Use of asthma drugs varies largely between countries as observed from the literature (Table 1). Part of this variability may be explained by differences in age distribution and type of data (i.e., surveys, prescriptions, dispensing), which hampers good comparisons between studies. To better explore differences in prescription rates of asthma drug use between countries, we conducted a retrospective cohort study in three European countries: the Netherlands, Italy, and UK, using the same methodology and stratifying by age, sex, and asthma diagnosis.

\section{Methods}

\section{Data collection}

Data were obtained from general practice medical record databases in three countries according to a common protocol. Databases were the Pedianet database in Italy [25], the Integrated Primary Care Information (IPCI) database in the Netherlands [39], and the Mediplus Disease AnalyzerMediplus database (IMS-DA) in the UK [42]. Details are described elsewhere [32]. Primary care in children is provided by the general practitioner (GP) in the UK and the Netherlands, and by a family pediatrician in Italy. These primary care medical record databases were chosen because they contain detailed information on the population, diagnoses, and prescriptions. The geographic location of the databases allowed us to study North and South European differences in drug prescribing.

\section{Study population}

The study population consisted of all children aged 0 18 years $(0-11$ years in Italy) during the study period 1 January 2000 until 31 December 2005 (1 January 2001 until 31 December 2005 for Italy).All persons needed to have a database history of $\geq 6$ months, except for children born during the study period. For each child, the personyears of follow-up were calculated, stratified by calendar year, age group, sex, and asthma diagnosis. For privacy issues, some databases only contain the year of birth, therefore age was assessed at the $1^{\text {st }}$ of January of each year, and in order to identify infants, preschoolers, and adolescents separately. We used modified the International Conference of Harmonization age categories to stratify by age $(<2, \geq 2-\leq 4,5-11$, and $\geq 12$ years of age) [17]. Each 


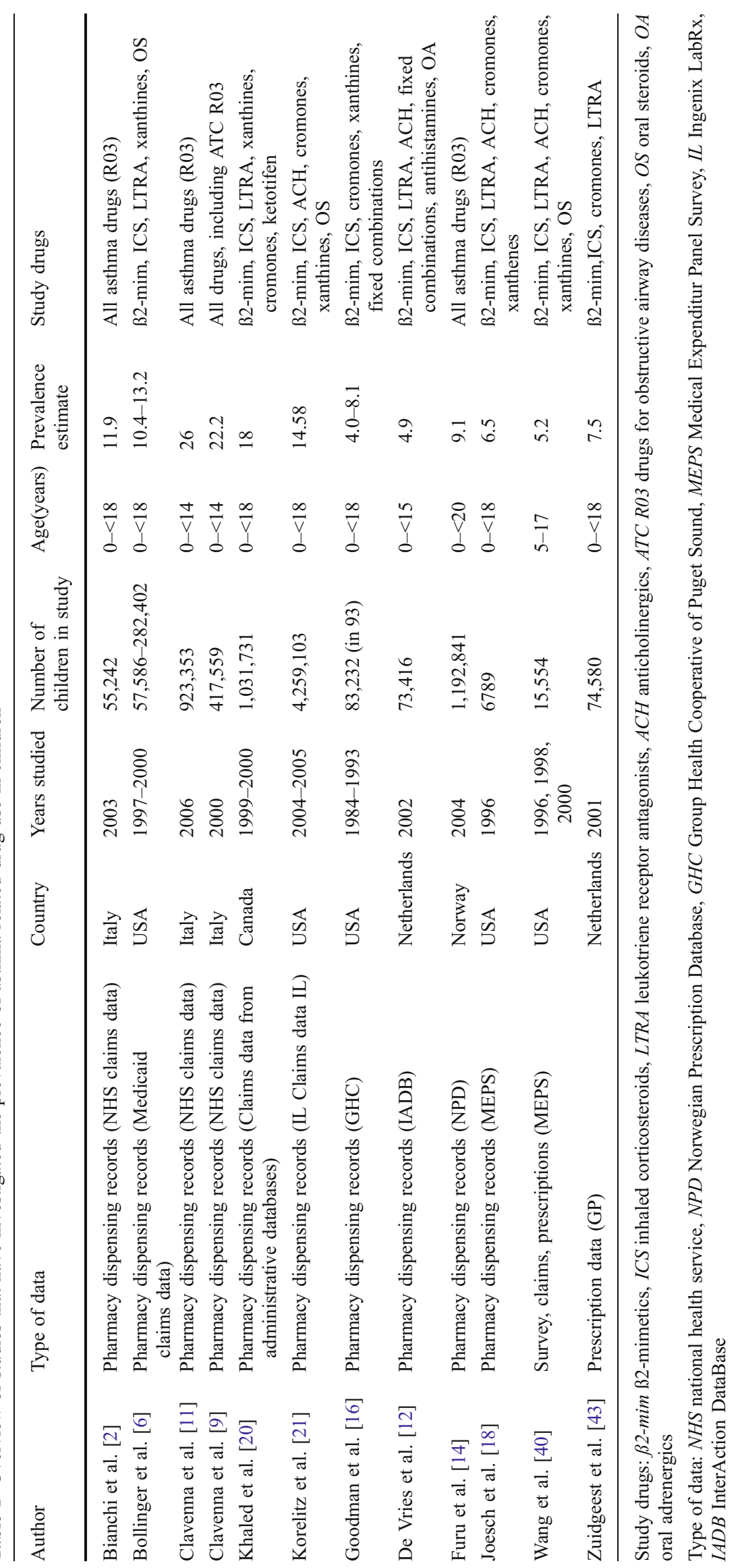


child was followed from the start of the study until the patient left practice or end of the study period (whichever was earliest).

\section{Assessment of asthma}

For each child, we assessed whether a diagnosis of asthma was made at anytime in its medical records using the following diagnostic codes: ICPC code R96 in IPCI, International Classification of Diseases (ICD)-9 code 493 in Pedianet and ICD-10 code J45 in IMS and free text [22, $36,37]$. If at any time during the follow-up asthma was diagnosed, the child was considered asthmatic for the entire period.

\section{Classification of prescriptions}

Drug prescriptions were categorized based on the World Health Organization's Anatomical Therapeutic Chemical (ATC) classification system [41]. All prescriptions for "obstructive airway diseases" (ATC R03) and "glucocorticosteroids for systemic use" (ATC H02AB) were obtained from the prescription files and further categorized into: B2-mimetics (either short-acting [SABA] or long-acting [LABA]), inhalation glucocorticosteroids, inhalation anticholinergics, fixed combination of SABA+short-acting anticholinergics, fixed combination of LABA+inhalation glucocorticosteroids, anti-allergic agents (best known as cromones), xanthines, and leukotriene receptor antagonists. Use of B2-mimetics+ICS was classified as a non-fixed combination if the child used B2-mimetics and an ICS in the same year. For each drug class, we calculated prevalence rates for the most frequently prescribed drugs (top three) by country.

Due to differences in labeling status between countries, off-label use was assessed per country. A drug was classified as being "off-label" if the child receiving the prescription had an age below the minimum age as specified in the summary product characteristics (SPC) or the drug was given for a different indication than specified in the SPC. This is in line with the new definition of pediatric off-label use provided by the Task Force in Europe for Drug development for Young [26].

\section{Statistical analysis}

Annual prevalence rates (per 1,000 PY or per 100 PY) of asthma drug use were calculated by counting the number of children using each drug or drug class by calendar year, age, sex, asthma status, and country and dividing this number by the number of person-years attributed by the different strata. User prevalence rates can be interpreted as the number of children per 1,000 children that uses a specific drug (class) during 1 year. If expressed per $100 \mathrm{PY}$ it can be freely translated as the percentage of children using these drugs in 1 year. The fact that we used annual prevalence rates means that a child who uses one drug (class) multiple times in 1 year, will be counted only once for that year. The use of person-years rather than persons in the denominator was necessary due to the dynamic nature of the cohort where persons could have variables durations of follow-up.

Differences in prescription rates between countries were tested by means of the $X^{2}$-test.

\section{Results}

Patient characteristics

Our population consisted of 671,831 children $(66 \%$ UK, $19 \%$ IT, $15 \%$ NL) of whom $49,442(7.4 \%)$ had asthma at any point during follow-up (Table 2).

\section{Asthma drug classes}

The user prevalence rate of any asthma drug was highest in young children and decreased with age (Figs. 1 and 2), it was highest in Italy for each age category. The difference between NL, the UK, and IT is largest for the youngest age categories with user prevalence rates of 25-30/100 PY in Italy, rates of 12 in the UK, and 10/100 PY in NL (Figs. 3 and 4). In the youngest age groups, prescription rates were higher for boys. This pattern switched in adolescence (between the ages 14 to 16 ), where user prevalence rates for almost all drug classes were higher in girls (Fig. 1).

B2-mimetics and ICS were each used by one to ten children per $100 \mathrm{PY}$ in all age categories in each country (Fig. 2). In Italy, prevalence of use of ICS was higher than use of B2-mimetics and even exceeded 10/100 PY in the youngest age group. The fixed combinations of anticholinergics + SABA were frequently used in the Netherlands and Italy but not in the UK, where mostly anticholinergics were used as single compound. Leukotriene receptor antagonists, anti-allergics, and xanthines were used by less than one child per 100 PY in each country and each age category, which is in concordance with protocols concerning asthma treatment. Fixed combinations of ICS + LABA were infrequently used in young children but exceeded 1/100 PY in adolescents in the Netherlands. Systemic use of steroids was very heterogeneous between countries. User rates exceeding 10/100 PY were observed in Italy, especially in the youngest children, whereas user rates were five- to eightfolds lower in the UK and almost 20-fold lower in the Netherlands. 
Table 2 Population size by country, age, sex, and asthma diagnosis

\begin{tabular}{|c|c|c|c|c|c|c|c|}
\hline \multirow{2}{*}{$\begin{array}{l}\text { Patient } \\
\text { characteristics }\end{array}$} & \multicolumn{2}{|l|}{ NL } & \multicolumn{2}{|l|}{ Italy $^{\mathrm{a}}$} & \multicolumn{2}{|l|}{ UK } & \multirow{2}{*}{$\begin{array}{l}\text { Total } \\
\text { Children with } \\
\text { asthma } \\
\text { No. }^{\text {b }} \% \text { of total) }\end{array}$} \\
\hline & $\begin{array}{l}\text { Children with } \\
\text { asthma } \\
\left.\text { No. }^{\text {b }} \% \text { of total }\right)\end{array}$ & $\begin{array}{l}\text { Total } \\
\text { population }\end{array}$ & $\begin{array}{l}\text { Children with } \\
\text { asthma } \\
\left.\text { No. }^{\text {b }} \% \text { of total }\right)\end{array}$ & $\begin{array}{l}\text { Total } \\
\text { population }\end{array}$ & $\begin{array}{l}\text { Children with } \\
\text { asthma } \\
\text { No. }^{\text {b }} \% \text { of total) }\end{array}$ & $\begin{array}{l}\text { Total } \\
\text { population }\end{array}$ & \\
\hline \multicolumn{8}{|l|}{ Age } \\
\hline$<2$ years & $2,165(8.4)$ & 25,694 & $2,539(4.6)$ & 54,999 & $2,977(3.8)$ & 79,246 & $7,681(5.7)$ \\
\hline$\geq 2-\leq 4$ years & $2,820(11.8)$ & 23,902 & $4,269(7.3)$ & 58,735 & $7,610(7.5)$ & 101,835 & $14,699(8.0)$ \\
\hline $5-\leq 11$ years & $5,545(11.7)$ & 47,435 & $5,399(7.5)$ & 72,264 & $19,856(12.8)$ & 155,488 & $30,800(11.2)$ \\
\hline $12-\leq 18$ years & $3,689(8.3)$ & 44,636 & & & $19,809(13.3)$ & 149,093 & $23,498(12.1)$ \\
\hline \multicolumn{8}{|l|}{ Sex } \\
\hline Females & $3,940(7.9)$ & 49,709 & $2,851(4.7)$ & 60,089 & $14,377(6.5)$ & 219,669 & $21,167(6.4)$ \\
\hline Males & $5,419(10.5)$ & 51,850 & $4,730(7.2)$ & 65,361 & $18,125(8.1)$ & 225,153 & $28,274(8.3)$ \\
\hline Total & $9,359(9.2)$ & 101,559 & $7,581(6.0)$ & 125,450 & $32,502(7.9)$ & 444,822 & $49,442(7.4)$ \\
\hline
\end{tabular}

$P Y$ person-years

${ }^{a}$ For Italy the age range included only $0-11$ years for the years 2001-2005

${ }^{b}$ The number of children in the various age groups does not add up to the total since one child can contribute to more than one age category during the study period

User prevalence rates for individual drugs

The prevalence of SABA use in children with asthma was similar in the Netherlands and Italy but much higher in the UK (30 vs. 60/100 PY). In children without asthma diagnosis, the prevalence was between one and eight per $100 \mathrm{PY}$. The most frequently prescribed SABAs were salbutamol and terbutaline in NL and the UK, whereas terbutaline was not frequently used in Italy (Table 3). User rates of LABA (this can be combined or single use) were very low $(<1 / 100 \mathrm{PY})$, but strongly increased with age in children with asthma. Most frequently used drugs were salmeterol and formoterol. In children without asthma, use of LABA was negligible
(Table 3 and Fig. 3). Single use of ß2-mimetics (without a prescription for ICS in the same year) was highest in the UK (195/1,000 PY in children with asthma and 23 in children without). In NL and IT prevalence rates were 127 and 75/ $1000 \mathrm{PY}$ in children with asthma and 12 and 18/1000 PY in children without an asthma diagnosis. In both countries prevalence rates decreased gradually with increasing age.

ICS were most frequently prescribed in Italy, especially in children $<2$ years of age. In children with asthma, ICS use was highest in the UK. The choice of drug differed; fluticasone was most often prescribed in NL and beclomethasone in the UK and Italy. Among the children with asthma who used 32 -mimetics, $42 \%$ were not prescribed
Fig. 1 Age, country, and sex specific user prevalence rates of asthma drugs (all ATC R03)

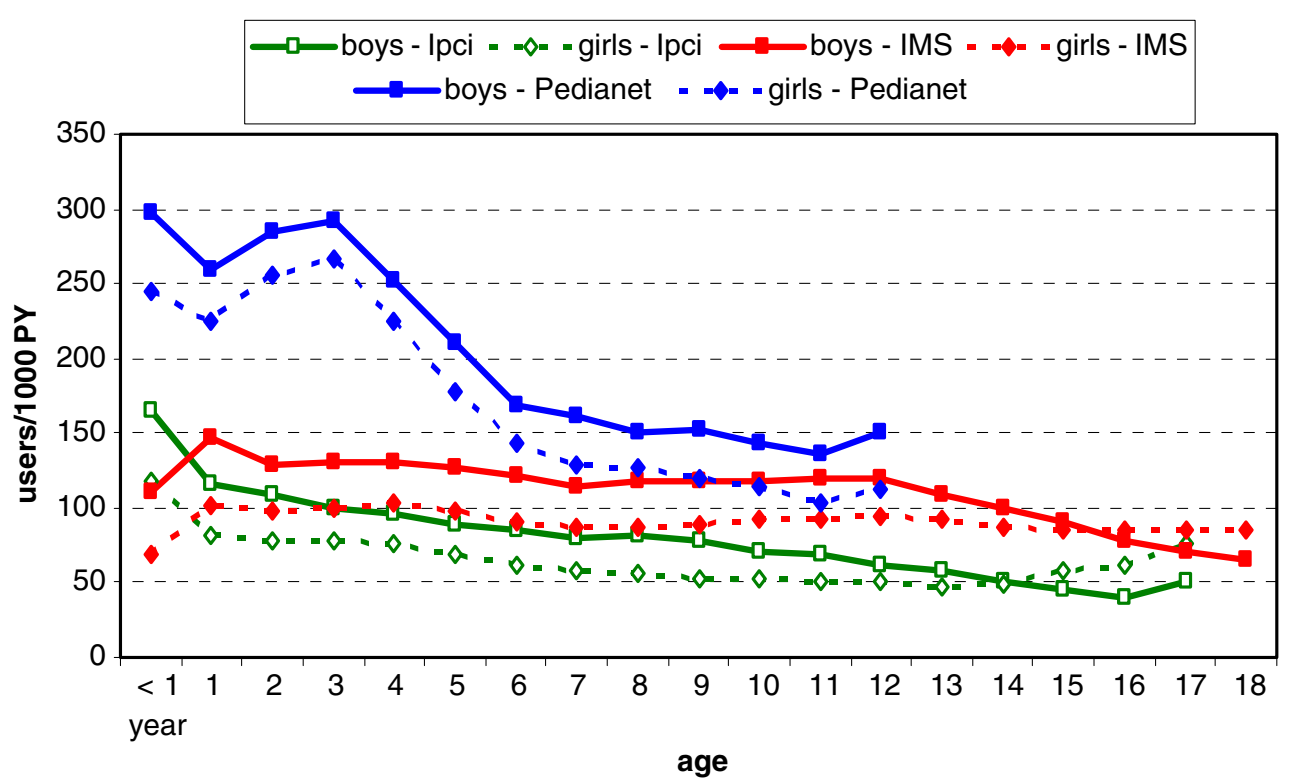




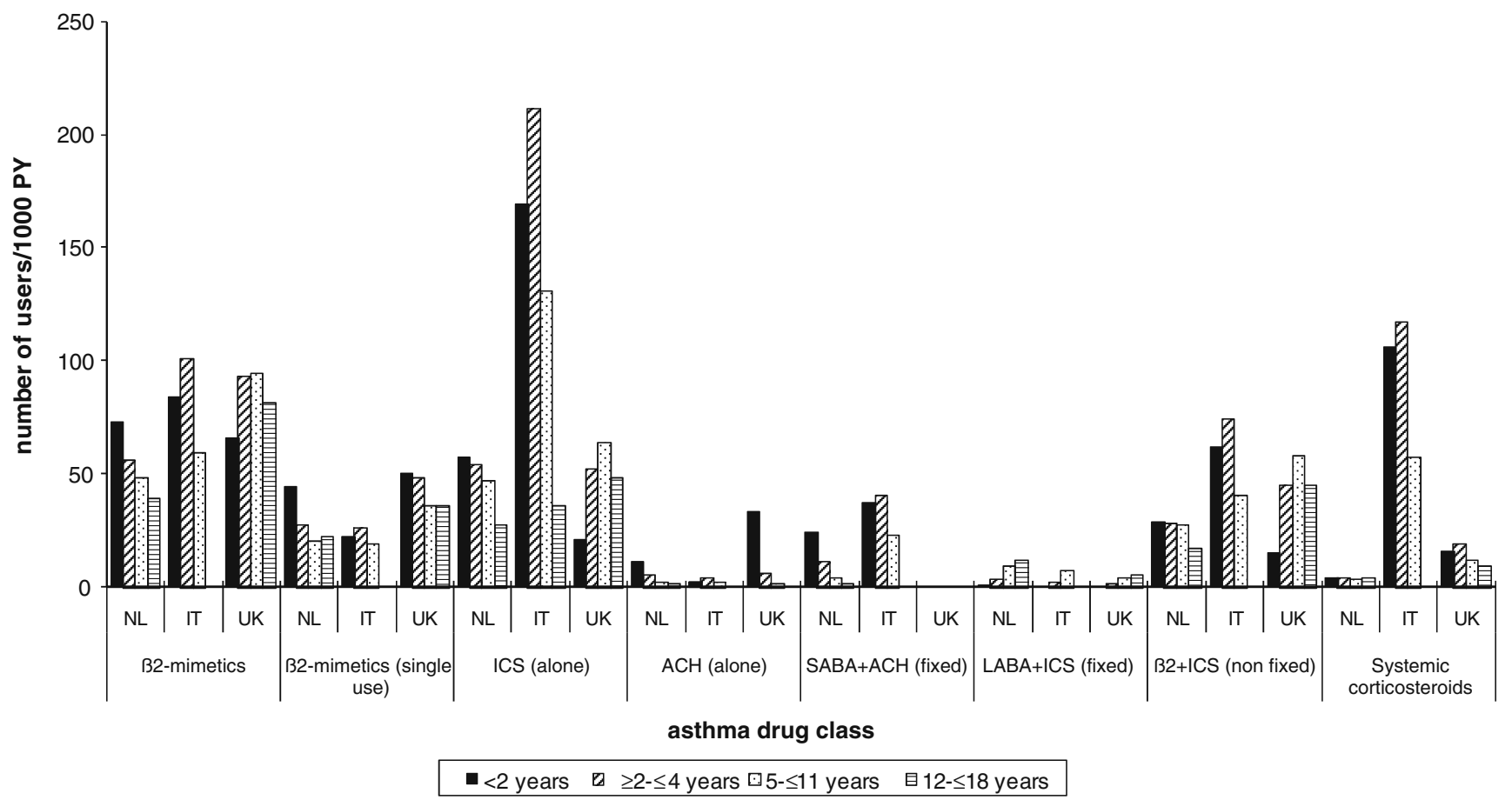

NL: the Netherlands, IT: Italy, UK: the United Kingdom, B2-mimetics: inhaled B2-mimetics (this can be single or non-fixed combination use), ICS: inhalation corticosteroids, $\mathrm{ACH}$ : anticholinergics, $\mathrm{SABA}+\mathrm{ACH}$ : fixed combinations of short-acting $\mathrm{B2}$-mimetics+anticholinergics, LABA+ICS: fixed combinations of long-acting B2-mimetics+inhalation corticosteroids, B2+ICS(non fixed): non-fixed combination of B2mimetics (LABA or SABA)+inhalation corticosteroids

Fig. 2 Annual user prevalence rates of the most frequently prescribed respiratory drugs

\section{children with asthma}

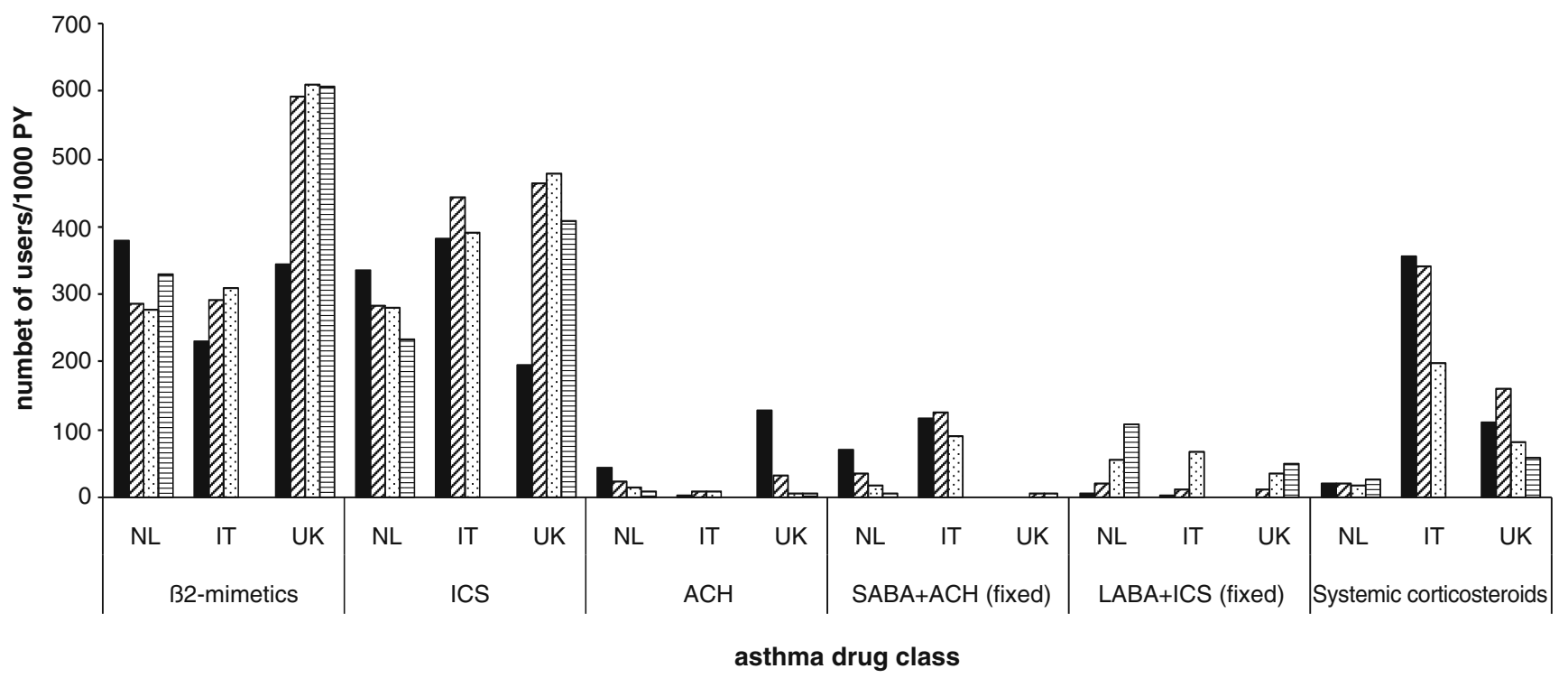

- $0-<2$ years $\square \geq 2-\leq 4$ years $\square>4-\leq 11$ years $\boxminus>11-\leq 18$ years

NL: the Netherlands, IT: Italy, UK: the United Kingdom, b2-mim= ß2-mimetics; ics=inhalation corticosteroids; ach=anticholinergics; saba+ach= fixed combination of short-acting B2-mimetics+anticholinergics; laba+ics= fixed combination of long-acting B2-mimetics+inhalation corticosteroids; scort=systemic corticosteroids

Fig. 3 Prevalence of respiratory drug use by age category and country in children with asthma 


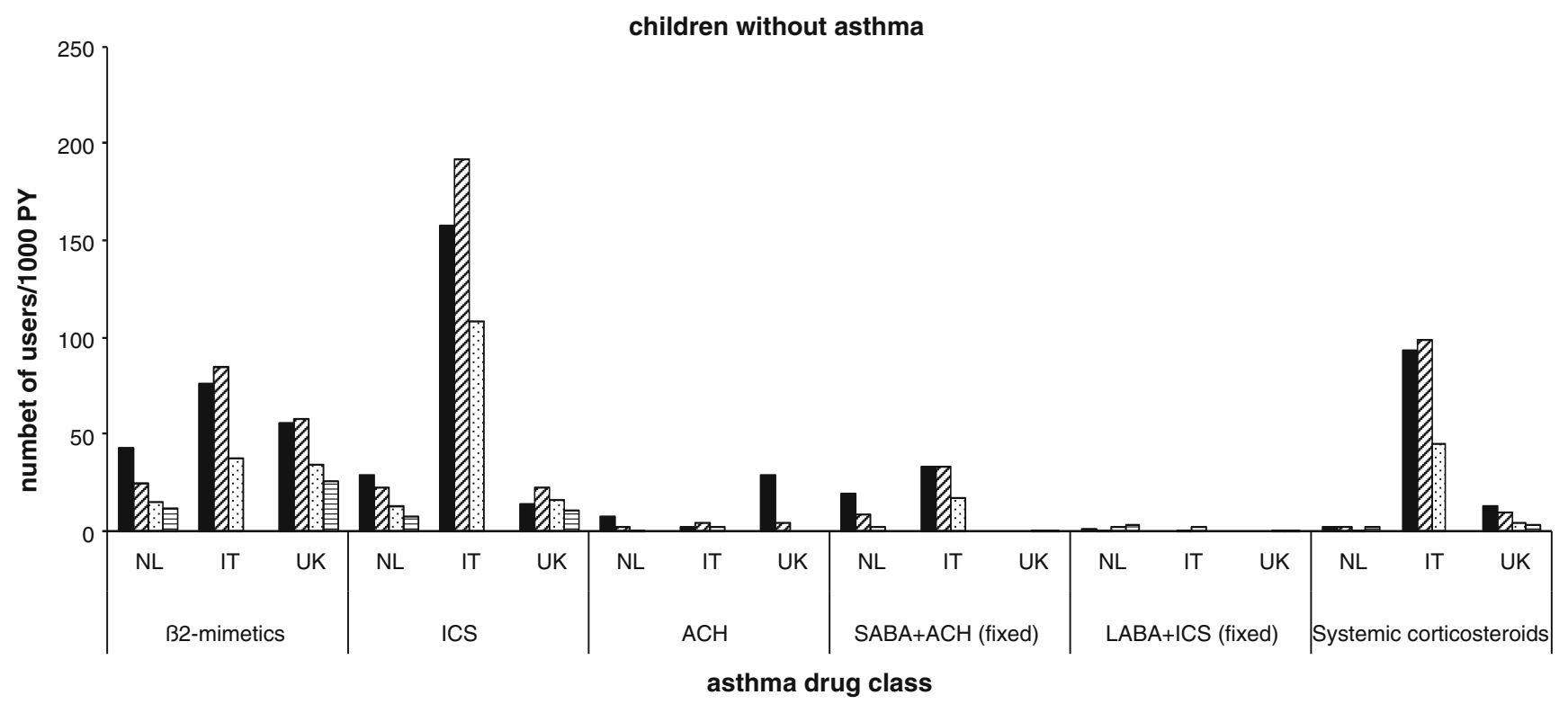

- $0-<2$ years $\quad 0 \geq 2-\leq 4$ years $\square>4-\leq 11$ years $\quad$ 目 $>11-\leq 18$ years

NL: the Netherlands, IT: Italy, UK: the United Kingdom, b2-mim= B2-mimetics; ics=inhalation corticosteroids; ach=anticholinergics; saba+ach = fixed combination of short-acting B2-mimetics+anticholinergics; laba+ics= fixed combination of long-acting 32 mimetics+inhalation corticosteroids; scort=systemic corticosteroids

Fig. 4 Prevalence of respiratory drug use by age category and country in children without asthma

ICS in that year in NL, 26\% in Italy, and 33\% in the UK. In children without asthma, ICS use was low in NL and the UK but reached rates of more than 10/100 PY in Italy.

Oral corticosteroid use was highest in Italy, with prescription rates of 26/100 PY in children with asthma and 7/100 PY in children without asthma. Rates were especially high in the younger age categories. In the other countries, prescription rates in children with asthma were much lower in each age category, both in children with and without asthma. The most frequently prescribed drugs were betamethasone in Italy and prednisolone in NL and the UK.

\section{Combination preparations}

Use of the fixed combinations of short-acting $\mathrm{SABA}+\mathrm{ACH}$ was low overall, but most frequent in Italy. Prescription rates decreased with age.

For the fixed combinations of ICS + LABA, use was highest in NL with six per $100 \mathrm{PY}$ in children with asthma. A clear increase of prescription rates with age was seen in all three countries.

Use of the loose combination of B2-mimetics +ICS was highest in IT $(55 / 1,000 \mathrm{PY})$, followed by the UK (48/ 1,000 PY) and NL (24/1,000 PY). In children with asthma prevalence rates were highest in the UK (404/1,000 PY), followed by IT (217) and NL (177)

\section{Off-label use}

Off-label use defined by use below the minimum age as specified in the SPC was investigated in Italy and NL. In Italy, salbutamol is indicated for use in children from the age of 18 months onwards, however user rates were 22.7/ 100 PY in children with asthma and 7.5 in children without asthma diagnosis below 18 months. In NL, off-label use was observed for the fixed combinations of B2-mimetics + anticholinergics. The minimum age for use of these drugs is 6 years in NL, however, prescription rates in children $<6$ years were 0.5-3.5/100 PY in NL (data not shown).

Off-label use defined as use for other indications than specified in the SPC (for drugs that only had asthma or COPD as indication) in children without recorded asthma diagnosis was observed in all three countries for several drugs (Table 4). In Italy, budesonide had the highest offlabel prescription rate; in NL, salbutamol; and in the UK, beclomathesone.

\section{Discussion}

This paper provides detailed information on asthma drug use in three European countries, and clearly demonstrates the similarities and differences in prescription rates. 
Table 3 Prevalence of respiratory drug use per country by treatment class and asthma diagnosis

\begin{tabular}{|c|c|c|c|c|c|c|c|c|}
\hline \multicolumn{3}{|l|}{ Netherlands } & \multicolumn{3}{|l|}{ Italy } & \multicolumn{3}{|l|}{ UK } \\
\hline & Asthma & No asthma & & Asthma & No asthma & & Asthma & No asthma \\
\hline \multicolumn{9}{|l|}{ SABA } \\
\hline Salbutamol & 276 & 19 & Salbutamol & 283 & 59 & Salbutamol & 519 & 32 \\
\hline Terbutaline & 39 & 2 & Terbutaline & 1.4 & 0.1 & Terbutaline & 88 & 2.8 \\
\hline Overall & 293 & 17 & & 284 & 59 & & 596 & 35 \\
\hline \multicolumn{9}{|l|}{ LABA } \\
\hline Salmeterol & 14 & 0.4 & Salmeterol & 13 & 0.5 & Salmeterol & 40 & 0.6 \\
\hline Formoterol & 7.6 & 0.2 & Formoterol & 1.6 & 0.1 & Formoterol & 2.5 & 0.02 \\
\hline Overall & 21 & 0.6 & & 15 & 0.6 & & 42 & 0.6 \\
\hline \multicolumn{9}{|l|}{ ICS } \\
\hline Fluticasone & 162 & 8 & Beclomethasone & 239 & 98 & Beclomethasone & 313 & 11 \\
\hline Budesonide & 68 & 4 & Fluticasone & 122 & 10 & Budesonide & 72 & 1.9 \\
\hline Beclomethasone & 50 & 2 & Flunisolide & 76 & 32 & Fluticasone & 63 & 1.5 \\
\hline Overall & 271 & 14 & & 404 & 143 & & 437 & 14 \\
\hline \multicolumn{9}{|l|}{ LTRA } \\
\hline \multirow[t]{2}{*}{ Montelukast } & 5.5 & 0.1 & Montelukast & 37 & 1.7 & Montelukast & 15 & 0.3 \\
\hline & & & Zafirlukast & 0.0 & 0.0 & Zafirlukast & 0.2 & 0.02 \\
\hline Overall & 5.5 & 0.1 & & 38 & 1.7 & & 15 & 0.3 \\
\hline \multicolumn{9}{|l|}{ Short-acting anticholinergics } \\
\hline \multirow[t]{2}{*}{ Ipratropium bromide } & 15.7 & 1.6 & Ipratropium & 6.2 & 2.4 & Ipratropium & 9.1 & 2.7 \\
\hline & & & Oxitropium & 0.3 & 0.1 & Oxitropium & 0.04 & 0 \\
\hline Overall & 16 & 1.6 & & 6.4 & 2.5 & & 9.1 & 2.7 \\
\hline \multicolumn{9}{|l|}{ ß2-agonists+ICS (non-fixed)* } \\
\hline & 177 & 5 & & 217 & 42 & & 404 & 12 \\
\hline \multicolumn{9}{|l|}{$\mathrm{SABA}+\mathrm{SACH}$ (fixed) } \\
\hline Fenoterol+Ipratropium & 19 & 4.1 & Salbutamol+Ipratropium & 104 & 25 & Salbutamol+Ipratropium & 0.7 & 0.06 \\
\hline Salbutamol+Ipratropium & 0.9 & 0.9 & Fenoterol+Ipratropium & 0.1 & 0.0 & Fenoterol+Ipratropium & 0.05 & 0 \\
\hline Overall & 20 & 4.4 & & 104 & 25 & & 0.07 & 0 \\
\hline \multicolumn{9}{|l|}{ LABA+ICS (fixed) } \\
\hline Salmeterol+Fluticasone & 33 & 1.3 & Salmeterol+Fluticasone & 37 & 1.3 & Salmeterol+Fluticasone & 31 & 0.5 \\
\hline Formoterol+Budesonide & 6.8 & 0.3 & Formoterol+Budesonide & 2.1 & 0.1 & Formoterol+Budesonide & 6.1 & 0.07 \\
\hline Overall & 60 & 2.3 & & 38 & 1.4 & & 37 & 0.6 \\
\hline
\end{tabular}

Asthma prevalence in children with asthma, no asthma prevalence in children without asthma, $S A B A$ short-acting $B 2$-mimetics, LABA long-acting B2-mimetics, ICS inhalation corticosteroids, LTRA leukotriene receptor antagonists, $\beta 2$-agonists + ICS (non-fixed) non-fixed combination of B2-mimetics + inhalation corticosteroids, $S A B A+S A C H$ (fixed) fixed combination of short-acting $B 2$-mimetics + short-acting anticholinergics, $L A B A+I C S$ (fixed) fixed combination of long-acting 32 -mimetics + inhalation corticosteroids

*Could either be the combination of LABA+ICS 1or SABA+ICS but always a loose combination (more than one device)

Whereas short-acting 32 -mimetics are the most frequently used drugs for treatment of asthma in the Netherlands and the UK, inhaled and systemic corticosteroids are most frequently used in Italy, especially in the youngest age groups. Longacting products, anticholinergics, xanthines, and LTRAs were, in general, infrequently prescribed in all countries.

Our data are in line with previous studies on asthma drug use in children, which also demonstrated that short-acting B2-mimetics and inhaled corticosteroids were prescribed most, but these studies often considered only one country or a region $[14,15]$, whereas our study captures multiple countries in different European regions. Our data also confirm findings of a recent survey showing high use of inhaled B2-mimetics in northern Europe and high usage of corticosteroids in southern Europe [4]. The north south gradient that we observed in the prescription of asthma drugs cannot be explained by country specific differences in asthma treatment protocols, as the protocols in the Netherlands; the UK and Italy are all based on the GINA guidelines.

There are various prescribing behaviors which deserve specific attention since they may be associated with a differential risk of adverse drug reactions. First of all, 


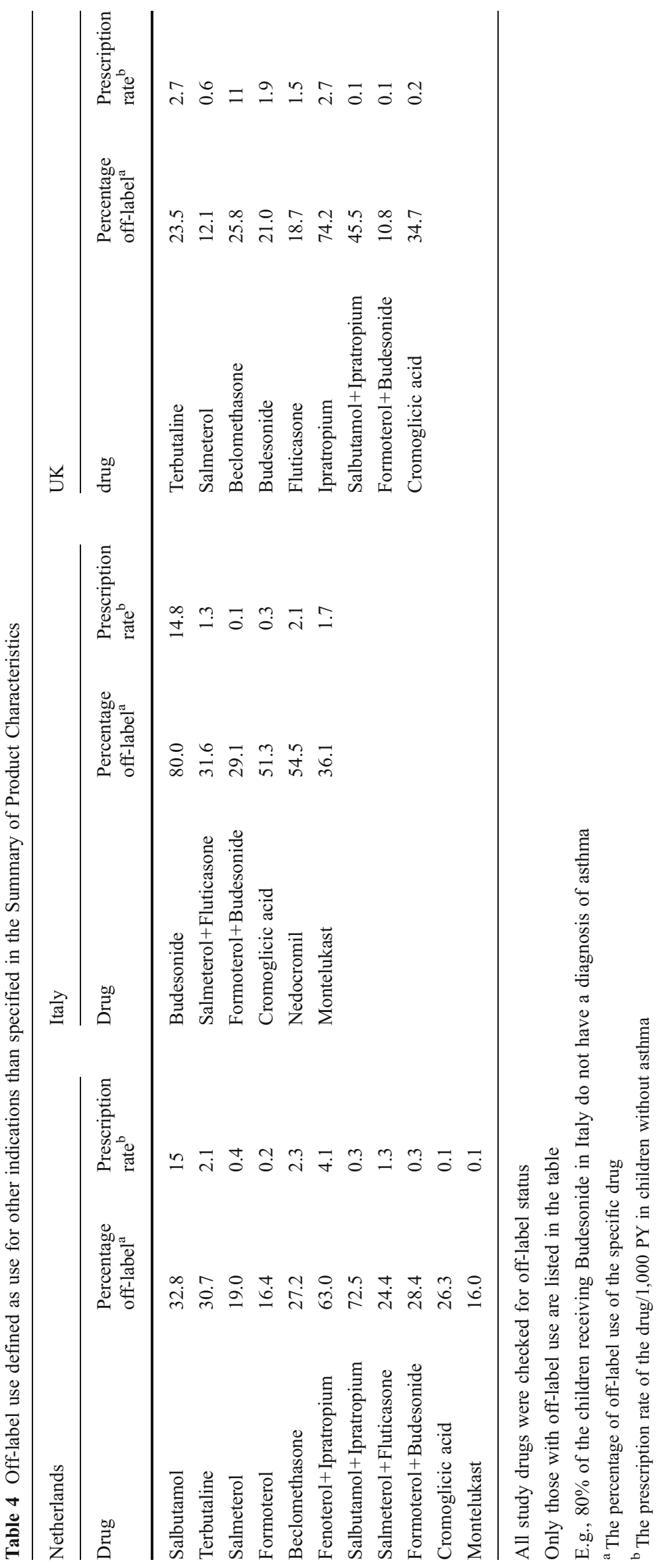


SABA use is high in the lower age categories which may at least partly be explained by the fact that they are recommended on an as-needed basis for acute wheezing in preschool children [7]. However, paradoxical responses like deterioration of asthma with use of these drugs have been reported in infants [34].

Secondly, prescription rates for long-acting 32 -mimetics were low for all three countries, which is in line with guidelines and recommendable since a black box warning was issued by the FDA due to safety issues in children, especially in monouse [13]. Thirdly, in children with asthma, the percentage of children using $\beta 2$-mimetics without ICS as controller was substantial, especially in the UK and Netherlands. A possible explanation could be that these children were intermittently treated with SABAs on an as-needed basis as defined in the first step of the guidelines [35]. However, chronic use of B2-mimetics without ICS is contraindicated in children with asthma because it may lead to increased airway inflammation and worsening of asthma control, and is in severe cases even associated with death [23, 29].

Fourth, use of ICS was very high in children under the age of five in Italy; this level of use certainly raises a question about potential overprescription, especially in children without asthma. However, a recent survey among children 1-5 years of age showed that southern Europe had the highest rate of wheezing symptoms $(48 \%)$ compared with northern Europe (29\%), which may explain some of the high use of ICS [4]. Although there is some evidence supporting the effectiveness of regular inhaled corticosteroids in preschool wheeze [5] its use remains controversial [7, 19]. Long-term use of steroids (inhaled and specifically oral) might cause side effects such as temporary growth retardation and adrenal suppression [1,35]. Less severe but more frequent and relevant side effects in children treated with ICS are oropharyngeal candidiasis, dysphonia, reflex cough, and pharyngitis [8].

Fifth, systemic corticosteroids are not the first choice of treatment in asthma and should only be used for exacerbations. A recent study showed that oral prednisolon and placebo did not differ in duration of hospitalization in children with mild to moderate wheezing associated with a viral infection [28]. Although the high use of oral steroids in Italy is consistent with previous study findings [2, 10, 35], it may be slightly overestimated. Betamethasone (dispensed as capsules) is often administered via a nebulizer, meaning that the actual oral use will be lower than reported, unfortunately we could not distinguish between these modes of administration.

Fixed combination therapies of an ICS + LABA are relatively new in the treatment of childhood asthma and their long-term safety is not well known. Use was highest in NL, similar to a recently reported increase in use of the fixed combination of ICS + LABA in Denmark [3]. Although fixed combination products of ICS + LABA are only licensed for use in children over 4 years, these drugs were also prescribed to children $<2$ years in the Netherlands. We found only one small retrospective study investigating the effect of a fixed combination of ICS + LABA in children $<4$ years, reporting a reduction in morbidity and an acceptable safety profile [30]. So far, the safety and efficacy data of the fixed combination of ICS +LABA in children $<2$ years is too scarce to justify prescribing these drugs in young children.

In general, off-label use of asthma drugs defined as use below the minimum age as reported in the SPCs was low except for the fixed combination of B2-mimetics+ anticholinergics in children $<6$ years in the Netherlands and the use of SABA in children $<18$ months in Italy. Prescription rates for asthma drugs in children without an asthma diagnosis are much lower than in children diagnosed with asthma but still surprisingly high, especially for ICS, and SABA. These drugs may have been used to treat wheezy young children with other respiratory conditions, such as respiratory tract infections (e.g., bronchiolitis) or first symptoms of undiagnosed asthma in young preschool children, but still, overuse cannot be excluded.

Use of asthma drugs is high, although very few long-term safety studies are available for children. The Pediatric Committee of the European Medicines Agency has recently published a pediatric needs list, containing drugs that are being used in children and where information on pharmacokinetics, efficacy, and safety is urgently needed [24]. This list includes frequently used respiratory drugs such as salbutamol, fluticasone, montelukast, and many others. Although randomized controlled trial (RCTs) are the gold standard for efficacy assessment, safety studies are more effectively conducted through large-scale postmarketing observational studies [31]. Clinical trials are often small and too short for safety assessment. Pharmacoepidemiological studies are a valid tool for assessing safety under real-life circumstances and often rely on secondary use of routine care data from claims databases and medical records. This study, as well as a previous inventory on databases with pediatric data, shows that exposure and outcome information is available on a large pediatric population [27, 32]. Pharmacoepidemiological studies should be promoted to improve the safety assessment of pediatric drugs since RCTs are hampered by methodological difficulties, especially in the pediatric subpopulation, and consequently, results may not be prompt and sufficient enough for safety assessment.

As for all observational research, our data has some limitations. First of all, as we used primary care data, we may not capture all specialist prescriptions in the UK and the Netherlands. This will minimally influence our results since asthma is a condition often dealt with in primary care, and asthma drugs originally prescribed by a specialist are often continued or prescribed by general practitioners [38]. Also, the health care provider in the studied countries differed: 
GP data from the UK and NL and family pediatrician data from IT. However, we do not believe that this would hinder comparability between databases as the nature of the databases is the same. If there are differences between countries, this reflects differences in primary care prescribing behavior and not in the type of data.

Furthermore, it is not possible to diagnose asthma in young preschool children and the diagnosis of asthma is often made at a later age, which could lead to misclassification of the indication in young children. However, to minimize the possibility of misclassification, we searched the entire medical record of a child for the diagnosis of asthma. If the diagnosis was made at a later age, the child was counted as having asthma during the whole study period.

To conclude, our results show high use of SABA and ICS, although not always combined, and low use of other asthma drugs. Safety data on specific asthma drugs are needed according to the European Medicines Agency [24]. This study underlines the potency of healthcare databases in rapidly providing data on pediatric drug use and possibly safety.

Acknowledgements We would like to thank Peter Stephens of IMS Health for providing the IMS-DA database. We thank all of the physicians contributing data to the PEDIANET, IPCI, and IMS-DA databases.

Conflicts of interest None of the authors has a conflict of interest. The principal investigator had full access to all of the data in the study and takes responsibility for their integrity and the accuracy of the data analysis.

Funding Funded by the European Community's 6th Framework Programme. Project number LSHB-CT-2005-005216: TEDDY: Task force in Europe for Drug Development for the Young.

Open Access This article is distributed under the terms of the Creative Commons Attribution Noncommercial License which permits any noncommercial use, distribution, and reproduction in any medium, provided the original author(s) and source are credited.

\section{References}

1. Bacharier LB, Boner A, Carlsen KH et al (2008) Diagnosis and treatment of asthma in childhood: a PRACTALL consensus report. Allergy 63(1):5-34

2. Bianchi M, Clavenna A, Labate L et al (2009) Anti-asthmatic drug prescriptions to an Italian paedriatic population. Pediatr Allergy Immunol 20(6):585-591

3. Bisgaard H, Szefler S (2006) Long-acting beta2 agonists and paediatric asthma. Lancet 367(9507):286-288

4. Bisgaard H, Szefler S (2007) Prevalence of asthma-like symptoms in young children. Pediatr Pulmonol 42(8):723-728

5. Bisgaard H, Gillies J, Groenewald M et al (1999) The effect of inhaled fluticasone propionate in the treatment of young asthmatic children: a dose comparison study. Am J Respir Crit Care Med 160(1):126-131
6. Bollinger ME, Smith SW, LoCasale R et al (2007) Transition to managed care impacts health care service utilization by children insured by Medicaid. J Asthma 44(9):717-722

7. Brand PL, Baraldi E, Bisgaard H et al (2008) Definition, assessment and treatment of wheezing disorders in preschool children: an evidence-based approach. Eur Respir J 32(4): 1096-1110

8. Buhl R (2006) Local oropharyngeal side effects of inhaled corticosteroids in patients with asthma. Allergy 61(5):518-526

9. Clavenna A, Rossi E, Berti A et al (2003) Inappropriate use of anti-asthmatic drugs in the Italian paediatric population. Eur J Clin Pharmacol 59(7):565-569

10. Clavenna A, Berti A, Gualandi L et al (2008) Drug utilisation profile in the Italian paediatric population. Eur J Pediatr 168:17380. doi:10.1007/s00431-008-0725-y

11. Clavenna A, Berti A, Gualandi L et al (2009) Drug utilisation profile in the Italian paediatric population. Eur J Pediatr 168(2):173-180

12. de Vries TW, Tobi H, Schirm E et al (2006) The gap between evidence-based medicine and daily practice in the management of paediatric asthma. A pharmacy-based population study from The Netherlands. Eur J Clin Pharmacol 62(1):51-55

13. FDA. FDA Public Health Advisory. Available from: http://www. fda.gov/cder/drug/advisory/LABA.htm

14. Furu K, Skurtveit S, Langhammer A et al (2007) Use of antiasthmatic medications as a proxy for prevalence of asthma in children and adolescents in Norway: a nationwide prescription database analysis. Eur J Clin Pharmacol 63(7):693-698

15. Gislason T, Olafsson O, Sigvaldason A (1997) Users of antiasthma drugs in Iceland: a drug utilization study. Eur Respir J 10(6):1230-1234

16. Goodman DC, Lozano P, Stukel TA et al (1999) Has asthma medication use in children become more frequent, more appropriate, or both? Pediatrics 104(2 Pt 1):187-194

17. ICH Guidelines. Available from: http://www.ich.org/cache/compo/ 276-254-1.html

18. Joesch JM, Kim H, Kieckhefer GM et al (2006) Does your child have asthma? Filled prescriptions and household report of child asthma. J Pediatr Health Care 20(6):374-383

19. Kaditis AG, Winnie G, Syrogiannopoulos GA (2007) Antiinflammatory pharmacotherapy for wheezing in preschool children. Pediatr Pulmonol 42(5):407-420

20. Khaled LA, Ahmad F, Brogan T, Fearnley J, Grahan J, MacLeod S, McCormick J (2003) Prescription medicine use by one million Canadian children. Paediatr Child Health 8:6A-56A

21. Korelitz JJ, Zito JM, Gavin NI et al (2008) Asthma-related medication use among children in the United States. Ann Allergy Asthma Immunol 100(3):222-229

22. Lamberts HWM, Hofmans-Okkes I (1993) The International Classification of Primary Care in the European Community. Oxford University Press, New York, p 242

23. Lanes SF, Garcia Rodriguez LA, Huerta C (2002) Respiratory medications and risk of asthma death. Thorax 57(8):683-686

24. List of paediatric needs (as established by the Paediatric Working Party). Available from: http://www.emea.europa.eu/htms/human/ paediatrics/inventory.htm

25. Menniti-Ippolito G, Raschetti R, Da Cas R et al (2000) Active monitoring of adverse drug reactions in children. Italian Paediatric Pharmacosurveillance Multicenter Group. Lancet 355:1613-1614

26. Neubert A BA, Catapano M, Baiardi P, Guiaquinto C, Knibbe C, Sturkenboom M CJM, Wong I CK, Ceci A, On behalf of the TEDDY Network of Excellence (2008) Defining Off-label and Unlicensed Use of Medicines for Children: Results of a Delphi survey. Pharmacol Res (In Press)

27. Neubert A, Sturkenboom MC, Murray ML et al (2008) Databases for pediatric medicine research in Europe - assessment and critical appraisal. Pharmacoepidemiol Drug Saf 17(12):1155-1167 
28. Panickar J, Lakhanpaul M, Lambert PC et al (2009) Oral prednisolone for preschool children with acute virus-induced wheezing. N Engl J Med 360(4):329-338

29. Salpeter SR, Ormiston TM, Salpeter EE (2004) Meta-analysis: respiratory tolerance to regular beta2-agonist use in patients with asthma. Ann Intern Med 140(10):802-813

30. Sekhsaria S, Alam M, Sait T et al (2004) Efficacy and safety of inhaled corticosteroids in combination with a long-acting beta2agonist in asthmatic children under age 5. J Asthma 41(5):575582

31. Sorensen HT, Lash TL, Rothman KJ (2006) Beyond randomized controlled trials: a critical comparison of trials with nonrandomized studies. Hepatology (Baltimore, Md) 44(5):1075-1082

32. Sturkenboom MC, Verhamme KM, Nicolosi A et al (2008) Drug use in children: cohort study in three European countries. BMJ 337:a2245

33. Szefler SJ (1991) Glucocorticoid therapy for asthma: clinical pharmacology. J Allergy Clin Immunol 88(2):147-165

34. Taylor DR, Sears MR, Cockcroft DW (1996) The beta-agonist controversy. Med Clin North Am 80(4):719-748

35. The Global Strategy for Asthma Management and Prevention, Global Initiative for Asthma (GINA) 2007.; Available from: http:// www.ginasthma.org
36. US Centers for Disease Control and Prevention. International Classification of Diseases, ninth revision, clinical modification (ICD-9-CM). Available from http://www.cdc.gov/nchs/icd/ icd $9 \mathrm{~cm} . h \mathrm{tm}$. Access date: 5 February 2010

37. US Centers for Disease Control and Prevention. International Classification of Diseases, Tenth Revision (ICD - 10). [cited 2010 16 June]; Available from: http://www.cdc.gov/nchs/icd/icd10.htm

38. van der Lei J, Duisterhout J, Westerhof H et al (1993) The introduction of computer-based patient records in the Netherlands. Ann Intern Med 119(10):1036-1041

39. Vlug AE, van der Lei J, Mosseveld BM et al (1999) Postmarketing surveillance based on electronic patient records: the IPCI project. Meth Inf Med 38(4-5):339-344

40. Wang LY, Zhong Y, Wheeler L (2006) Asthma medication use in school-aged children. J Asthma 43(7):495-499

41. WHO Collaborating Center for Drug Satistics Methodology. Available from: http://www.whocc.no/atcddd/

42. Wong I, Murray M (2005) The potential of UK clinical databases in enhancing paediatric medication research. Br J Clin Pharmacol 59(6):750-755

43. Zuidgeest MG, van Dijk L, Smit HA et al (2008) Prescription of respiratory medication without an asthma diagnosis in children: a population based study. BMC Health Serv Res 8:16 